\title{
Dual Thermo- and pH-responsive Behavior of Double Zwitterionic Graft Copolymers for Suppression of Protein Aggregation and Protein Release
}

\author{
Dandan $\mathrm{Zhao}^{\dagger}$, Robin Rajan ${ }^{\dagger}$ and Kazuaki Matsumura ${ }^{* \dagger}$ \\ $\uparrow$ School of Materials Science, Japan Advanced Institute of Science and Technology, \\ 1-1 Asahidai, Nomi, Ishikawa 923-1292, Japan
}

Corresponding Author: Kazuaki Matsumura

Email: $\underline{\text { mkazuaki@jaist.ac.jp. }}$ 


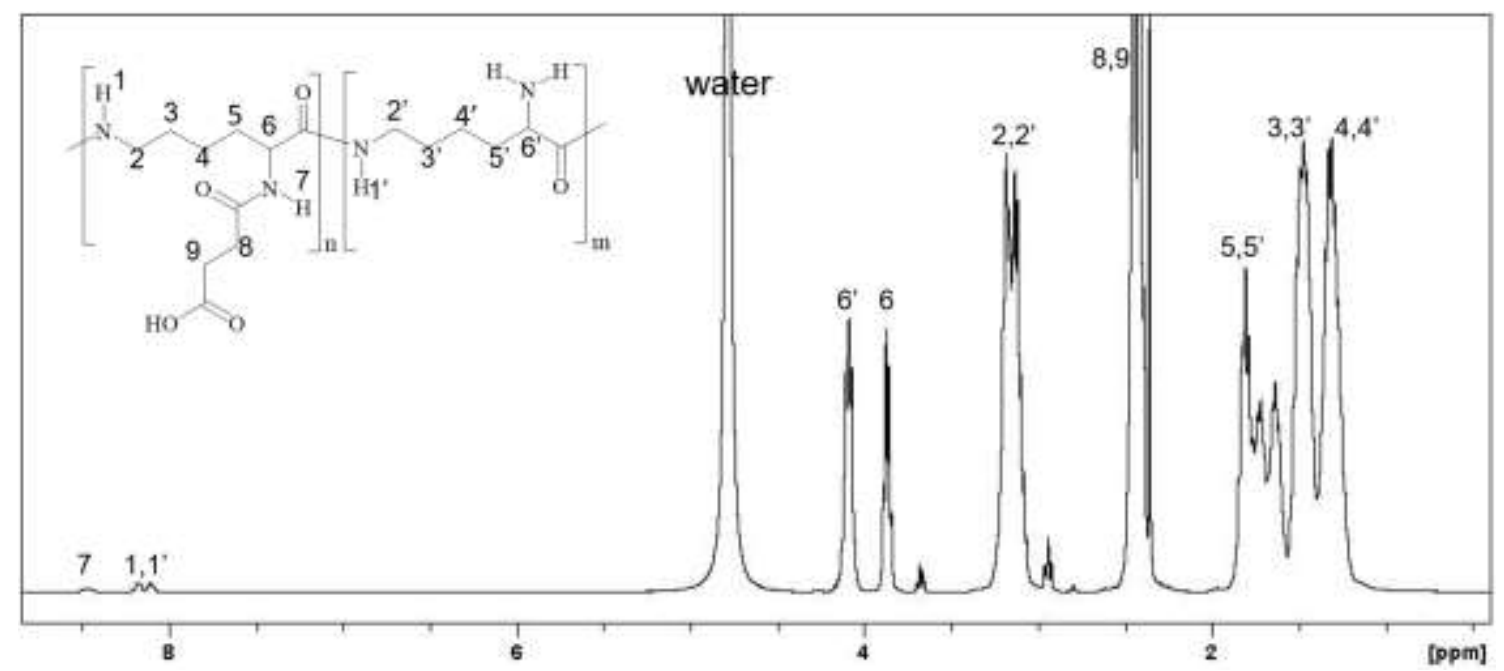

Figure S1. ${ }^{1} \mathrm{H}$ NMR of PLLSA in $\mathrm{D}_{2} \mathrm{O}$

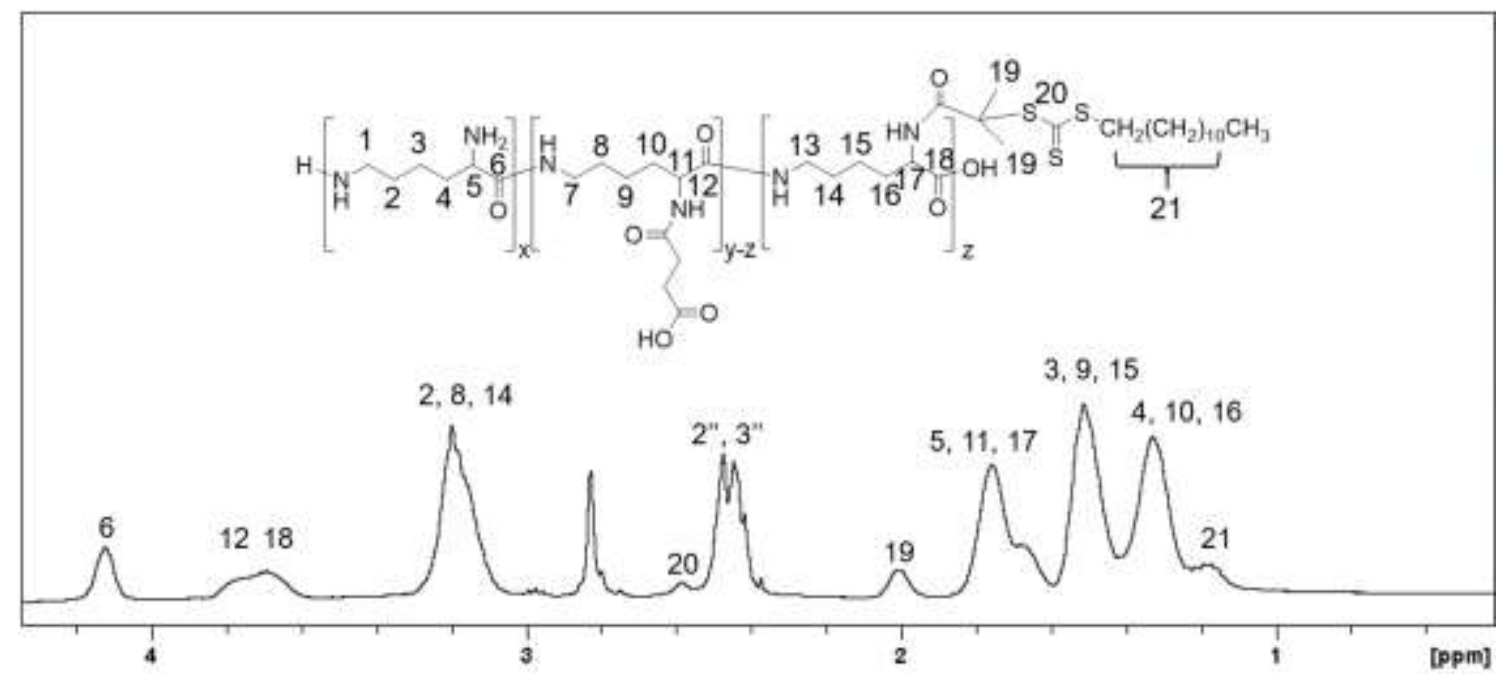

Figure S2. ${ }^{1} \mathrm{H}$ NMR of Macro-CTA in $\mathrm{D}_{2} \mathrm{O}$ 


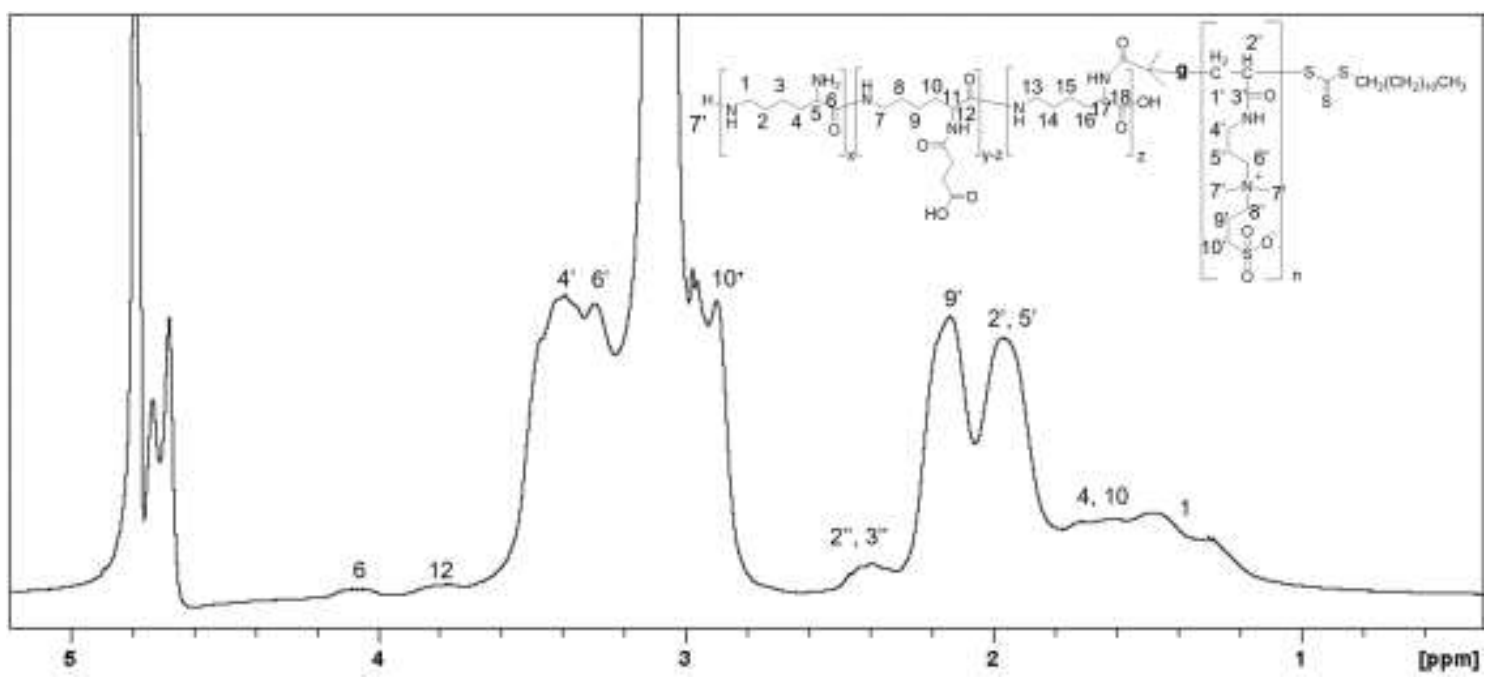

Figure S3. ${ }^{1} \mathrm{H}$ NMR of $\mathrm{P} 1$ in $\mathrm{D}_{2} \mathrm{O}$

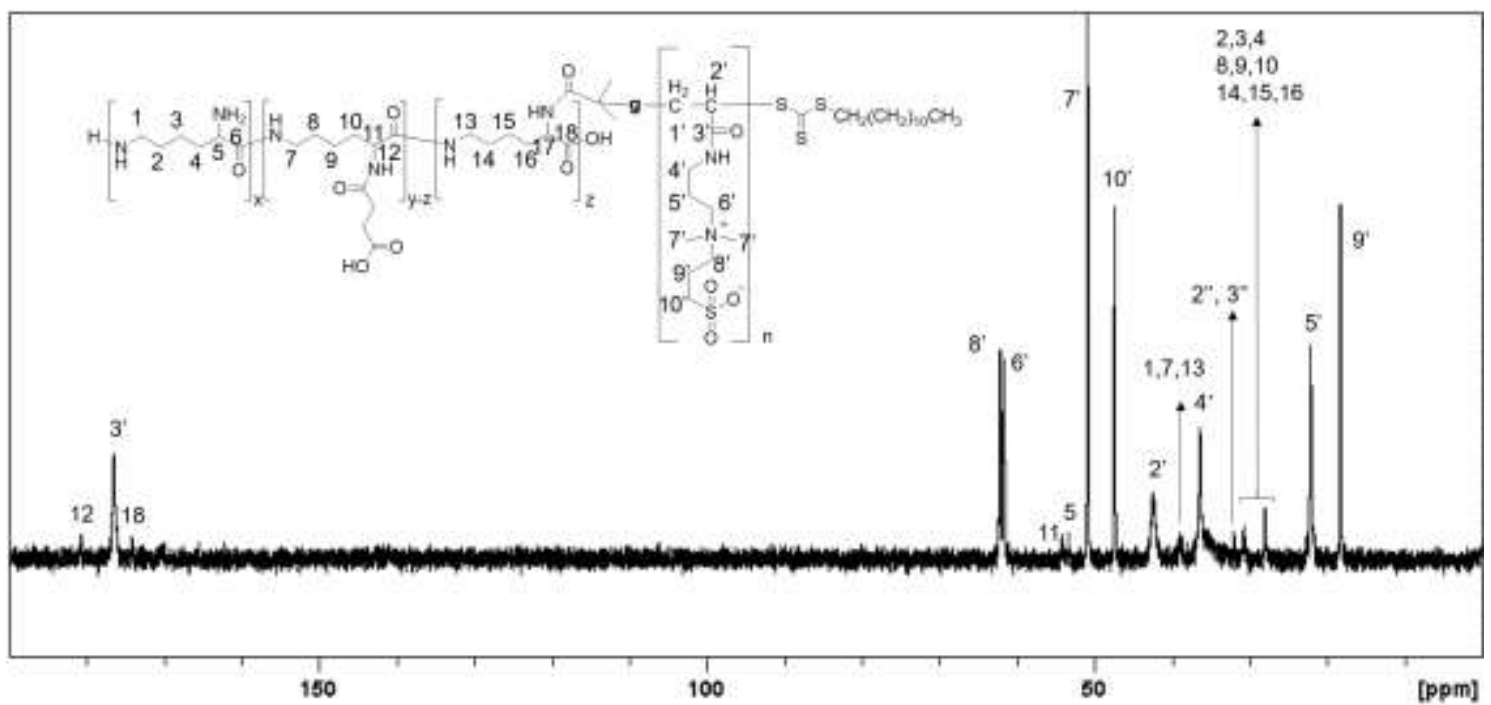

Figure S4. ${ }^{13} \mathrm{C}$ NMR of $\mathrm{P} 1$ in $\mathrm{D}_{2} \mathrm{O}$ 


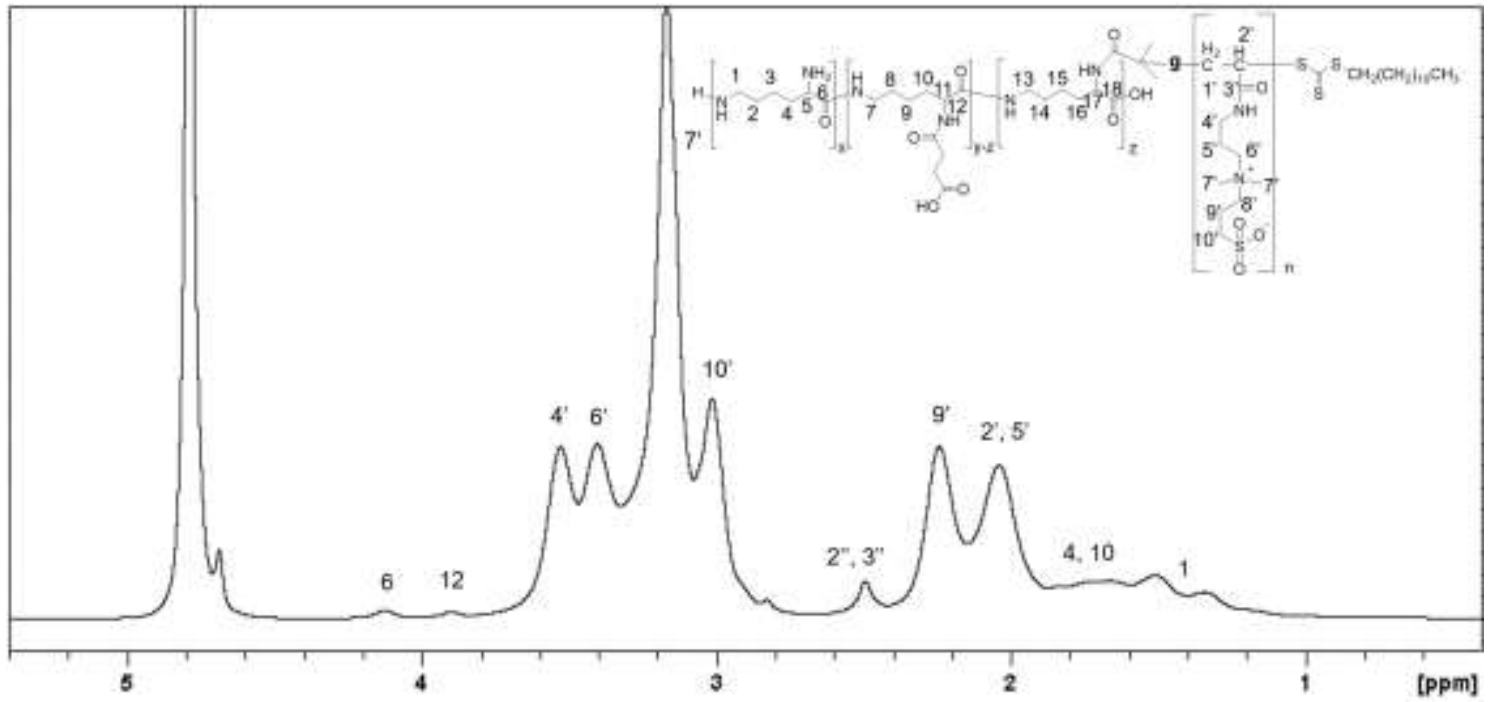

Figure S5. ${ }^{1} \mathrm{H}$ NMR of $\mathrm{P} 2$ in $\mathrm{D}_{2} \mathrm{O}$

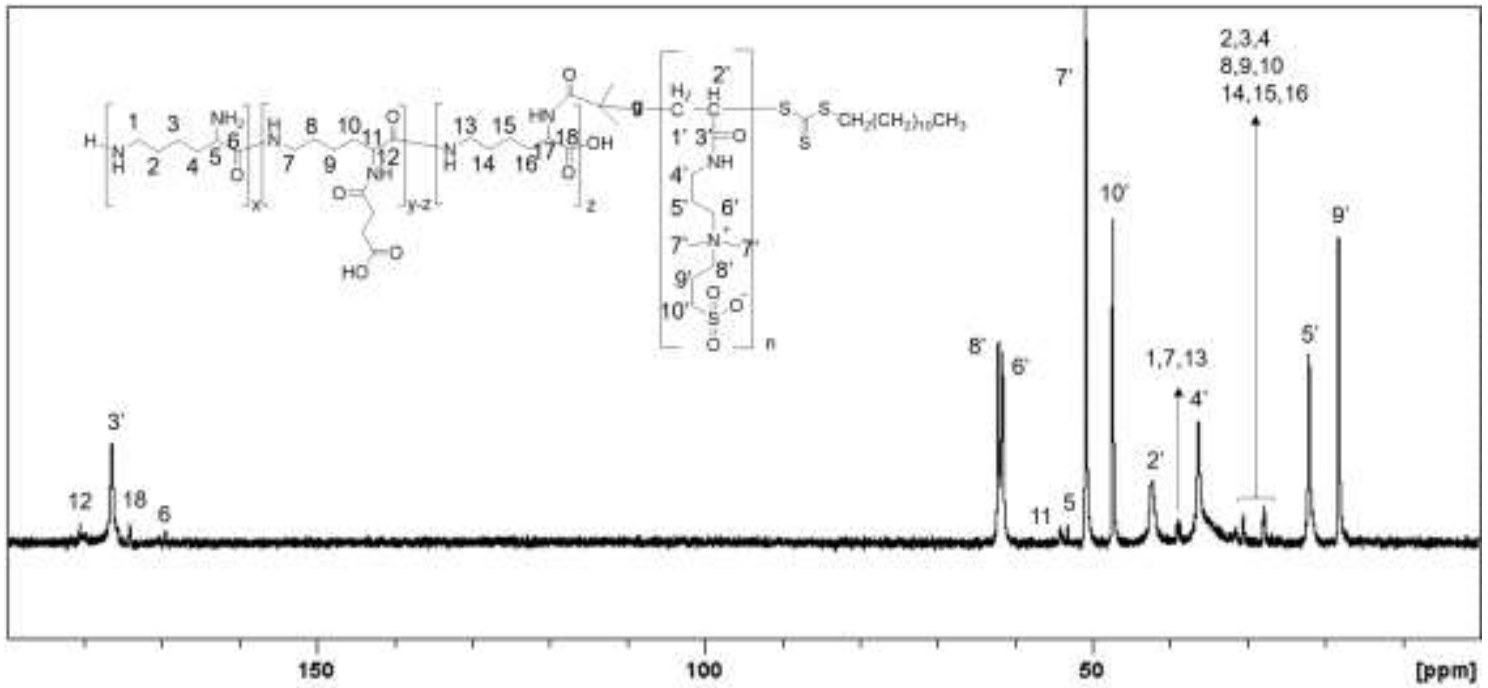

Figure S6. ${ }^{13} \mathrm{C}$ NMR of $\mathrm{P} 2$ in $\mathrm{D}_{2} \mathrm{O}$ 


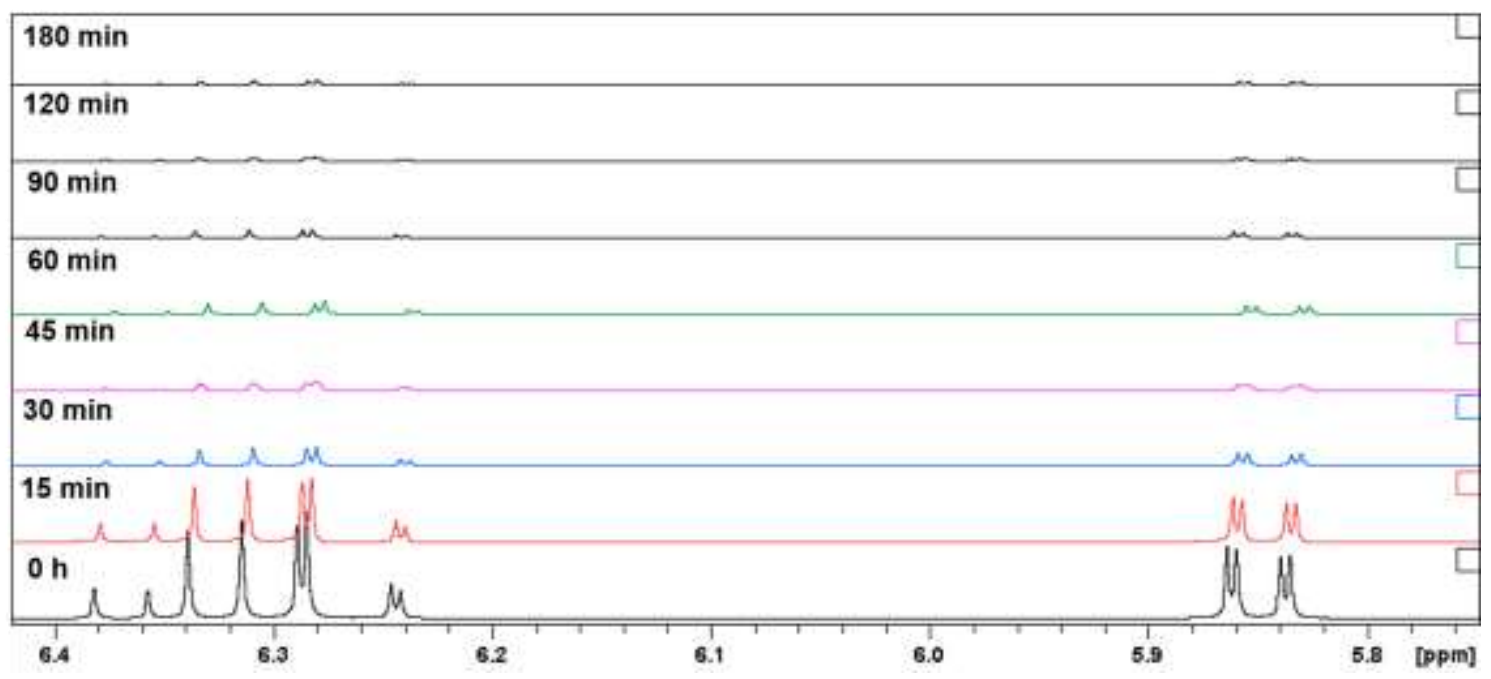

Figure S7. Time-dependent ${ }^{1} \mathrm{H}-\mathrm{NMR}$ spectra of $\mathrm{P} 1$ in $\mathrm{D}_{2} \mathrm{O}$

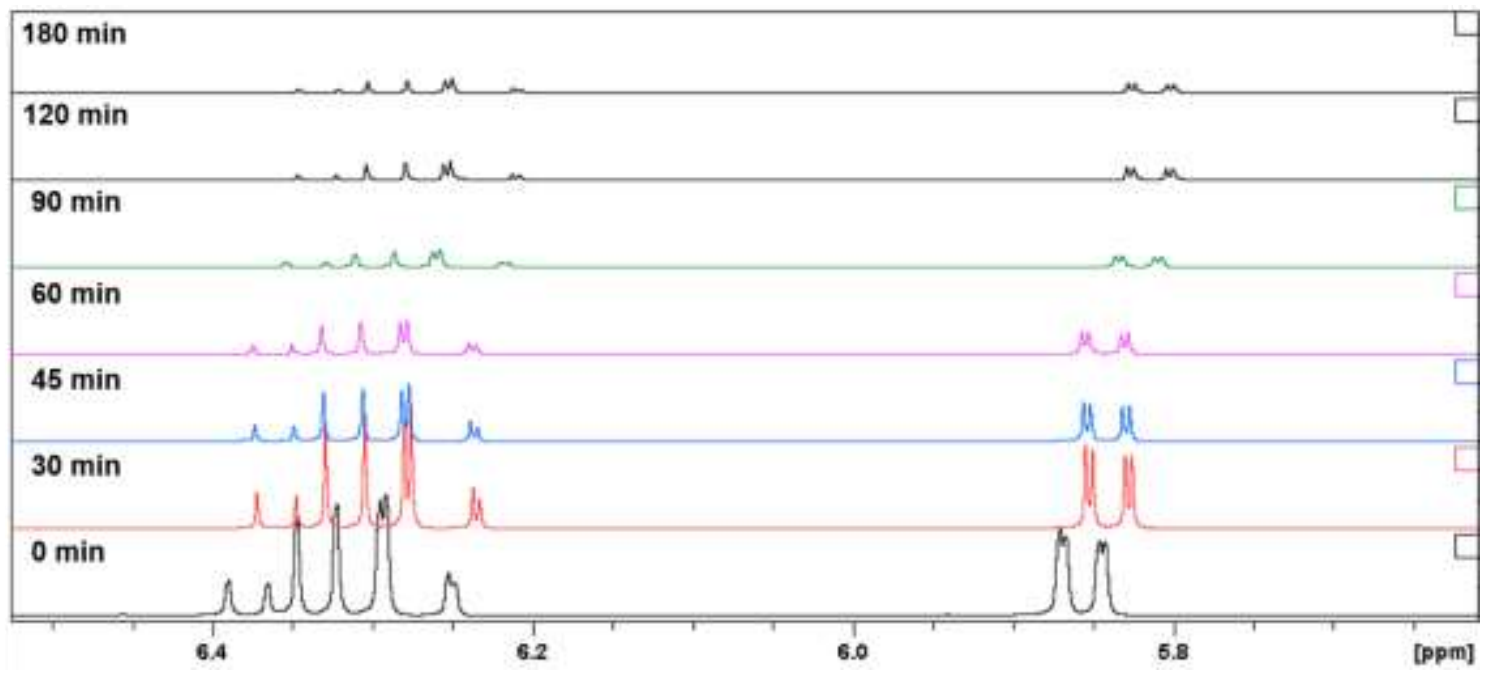

Figure S8. Time-dependent ${ }^{1} \mathrm{H}-\mathrm{NMR}$ spectra of $\mathrm{P} 2$ in $\mathrm{D}_{2} \mathrm{O}$
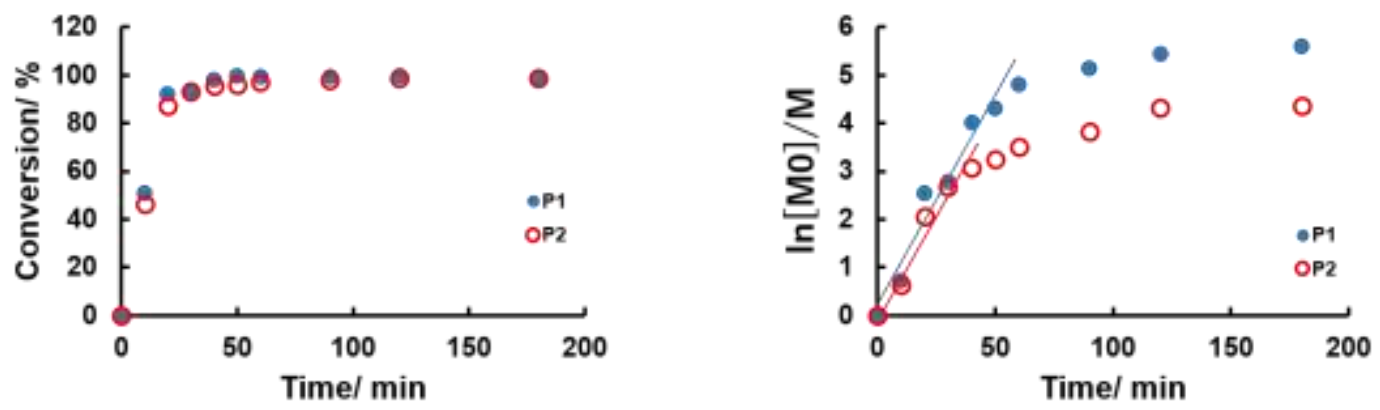

Figure S9. Kinetic plot showing the polymerization of the block copolymer. 

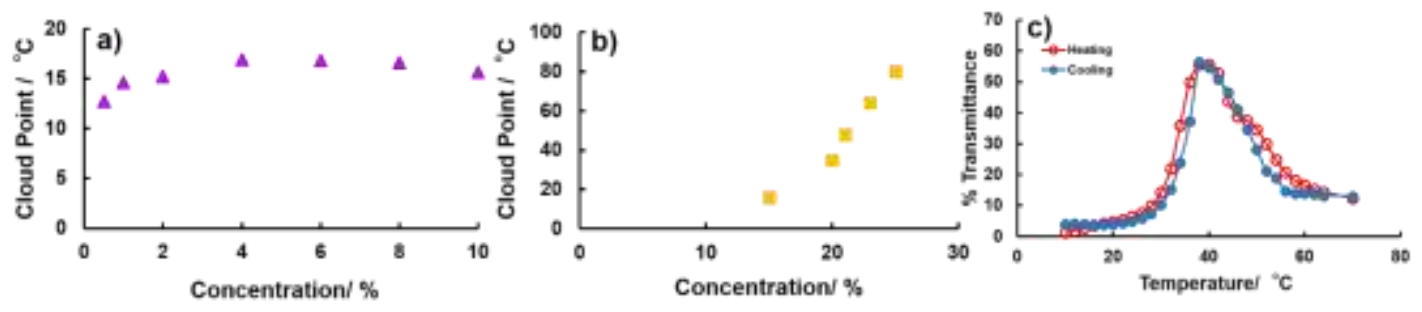

Figure S10. Phase diagrams of a) PSPB homopolymer solution and b) PLLSA50 polymer solution. c) Hysteresis curves of 2\% (w/w) P1 in distilled water. Red line: heating; blue line: cooling.
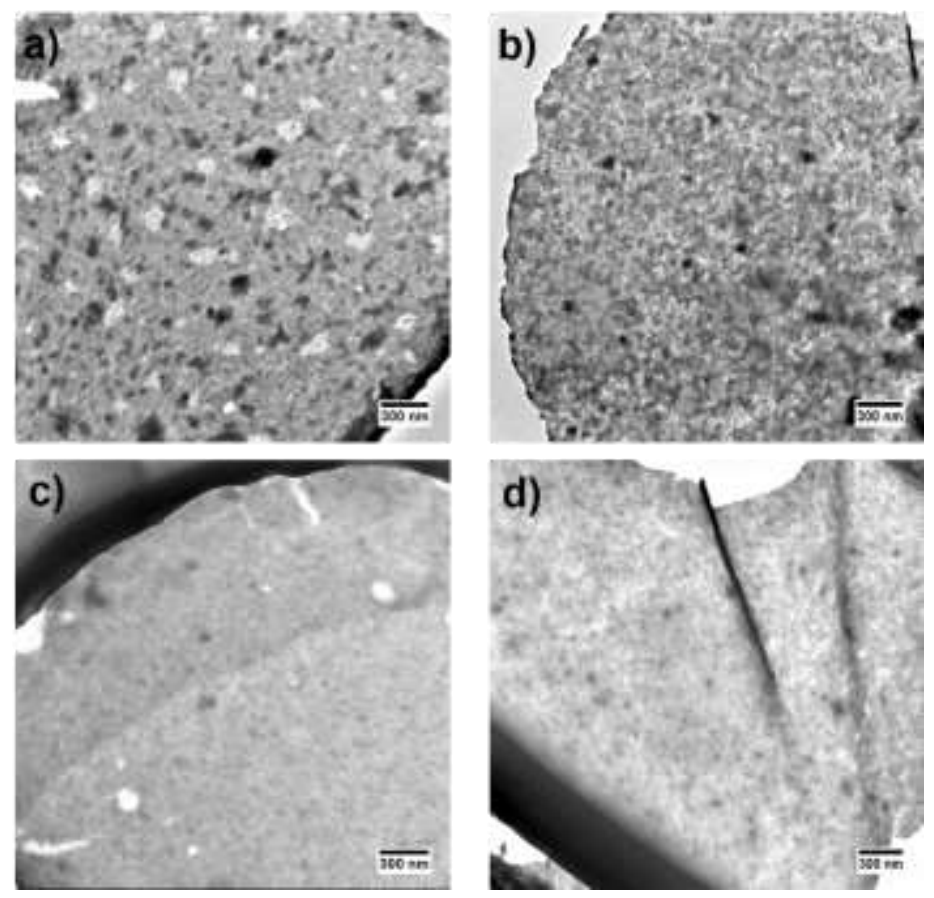

Figure S11. TEM image of P1 (a and b) and P2 (c and d) from a solution of concentration $0.1 \%$ at temperature $4{ }^{\circ} \mathrm{C}$ (a and c) and temperature $70{ }^{\circ} \mathrm{C}$ (b and d). Bars; $300 \mathrm{~nm}$ 


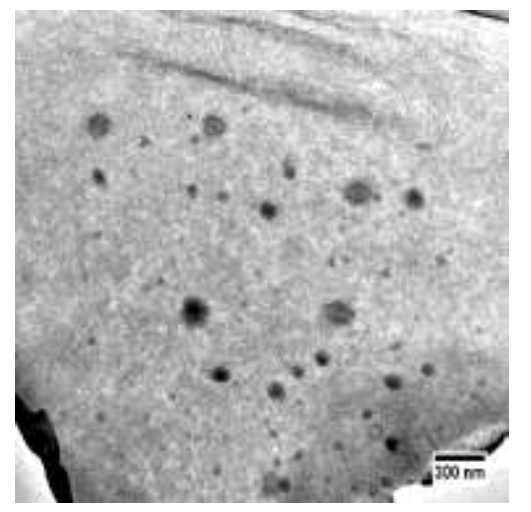

Figure S12. TEM image of P2-lysozyme hybrids. The concentrations of P2 and lysozyme were 5\% (w/w) and $0.3 \%(\mathrm{w} / \mathrm{w})$, respectively, in PBS $(\mathrm{pH}=7.4)$ after heating at $90{ }^{\circ} \mathrm{C}$ for $30 \mathrm{~min}$. Bar; $300 \mathrm{~nm}$. 